\title{
Admixture in Africanized honey bees (Apis mellifera) from Panamá to San Diego, California (U.S.A.)
}

\author{
Daniela Zarate ${ }^{1}$, Thiago Lima ${ }^{2}$, Jude Poole ${ }^{3}$, Erin Calfee ${ }^{4}$, Ronald Burton ${ }^{5}$, and Joshua \\ $\mathrm{Kohn}^{3}$ \\ ${ }^{1}$ UC San Diego \\ ${ }^{2}$ University of California San Diego Scripps Institution of Oceanography \\ ${ }^{3}$ University of California San Diego \\ ${ }^{4}$ University of California Davis \\ ${ }^{5}$ Scripps Institution of Oceanography
}

February 12, 2021

\begin{abstract}
The Africanized honey bee (AHB) is a New World amalgamation of several subspecies of the western honey bee (Apis mellifera), a diverse taxon grouped into four major biogeographic lineages: A (African), M (western European), C (eastern European), and O (Middle Eastern). In 1956, accidental release of experimentally bred "Africanized" hybrids from a research apiary in Sao Paulo, Brazil initiated a hybrid species expansion that now extends from northern Argentina to northern California (U.S.A.). Here, we assess nuclear admixture and mitochondrial ancestry in 15 bees from each of four regions across this expansive range: the Isthmus of Panamá; Guanacaste, Costa Rica, Tapachula, Mexico; and San Diego, U.S.A to assess ancestry of AHB several decades following initial introduction and test the prediction that African ancestry decreases with increasing latitude. We find that AHB nuclear genomes from Central America and Mexico have majority African ancestry (Mexico, 79\%; Costa Rica 90\%; and Panamá 94\%) with varying contributions from western and eastern European lineages. AHB from San Diego (CA) show markedly lower African ancestry (40\%) with substantial genomic contributions from all four major honey bee lineages. The mitochondria of all bees sampled in Costa Rica and Panamá originated in Africa. The majority (11) of bees sampled in Mexico carried African mitochondria with the remainder carrying eastern European mitochondria. In the San Diego population, mitochondria from all four lineages are present. Genetic diversity measures from all New World populations are similar and exceed those of ancestral forms. The unique genetic makeup of the San Diego honey bee population makes it a rich source of genetic material for honey bee breeding.
\end{abstract}

\section{Hosted file}

Admixture_in_Africanized_Honey_Bees_-_Zarate_Submission.pdf available at https://authorea. com/users/395259/articles/508562-admixture-in-africanized-honey-bees-apis-melliferafrom-panam $\%$ C3\%A1-to-san-diego-california-u-s-a 